\section{RECURRENT CEREBRAL INFARCTION AND CEN. TRAL RETINAL ARTERY OCCLUSION FOLLOWING MANDIBULAR ZOSTER}

\section{To the Editor:}

The syndrome of delayed contralateral hemiparesis following ophthalmic zoster (DCH) is well recognised and has been shown to be due to focal or multifocal vasculitis. ${ }^{1}$ The syndrome is typically self-limiting and carries a good prognosis. We report a patient with mandibular zoster and lymphoma, in whom two episodes of contralateral hemiparesis and an ipsilateral central retinal artery occlusion occurred over a fifteen week period.

A 43-year-old woman was admitted with a sudden right hemiparesis. A diagnosis of prolymphocytic lymphoma was made eleven months previously and a course of cytotoxic therapy was completed two months prior to admission. Seven weeks prior to admission she developed left mandibular herpes zoster which resolved in a few days. Cerebrospinal fluid examination seven days after admission showed a cell count of 13 lymphocytes $/ \mathrm{mm}^{3}$ and a protein of $75 \mathrm{mg} / \mathrm{dL}$. Computed tomographic (CT) scan of the brain showed a low attenuation, non-enhancing area in the left corona radiata consistent with an infarct. An echocardiogram was normal. The patient improved and was discharged seven weeks later walking with a cane. Two weeks after starting a further course of chemotherapy she presented with herpes zoster of the left T10 dermatome which resolved in a few days. Four weeks later the patient was admitted with a recurrent right hemiparesis. CT scan now showed a second low attenuation area in the left corona radiata. Cerebrospinal fluid examination showed a cell count of 11 lymphocytes $/ \mathrm{mm}^{3}$ and a protein of $63 \mathrm{mg} / \mathrm{dL}$. Nine days later she complained of blurring of vision of her left eye, and a week later this suddenly developed blindness in this eye. The visual acuity was reduced to light perception only and fundoscopy showed disc pallor and attenuated arteries compatible with a central retinal artery occlusion. Carotid angiography showed a localised stenosis of the M1 segment of the left middle cerebral artery typical of arteritis following DCH. ${ }^{1}$ The carotid bifurcations were normal. The patient died three months later from lymphomatous infiltration of the terminal ileum. Autopsy was declined.

Arterial histopathology in DCH is similar to that in granulomatous angiitis of the nervous system (GANS) although the etiology of GANS is unknown. Unlike the monophasic illness typically seen in DCH, GANS has a progressive clinical course and a high mortality. ${ }^{1}$ Our patient had a clinical course that was atypical for DCH. Only two of 39 other reported cases of DCH have had a recurrent ischemic event and these occurred within a month. 1 There have been no reports of $\mathrm{DCH}$ following mandibular or thoracic zoster and only one other case of central retinal artery occlusion has been reported, following ophthalmic zoster. ${ }^{2}$

In our patient, herpes zoster was associated with lymphoma. Cutaneous zoster is more severe and disseminates more frequently in patients with lymphoma. Whereas no cases of lymphoma were found in a series of 86 patients with herpes zoster ophthalmicus, ${ }^{3} 10 \%$ of the 39 cases of DCH in the literature have had associated lymphoma' ${ }^{1}$ and $30 \%$ (three of ten) of the reported patients who developed GANS after herpes zoster had lymphoma. ${ }^{4}$ Immunosuppression secondary to lymphoma may thus have encouraged both the development of DCH in our patient and the unusual subsequent clinical course.

\section{Patrick Pullicino and Stephen Fava \\ Department of Medicine University of Malta and St. Luke's Hospital \\ Gwardamangia, Malra}

1. Sigal $\mathbf{L H}$. The neurologic presentation of vasculitic and rheumatologic syndromes. Medicine (Baltimore) 1987; 66: 157-180.

2. Hall S, Carlin L, Roach ES, McLean WT Jr. Herpes zoster and central retinal artery occlusion. Ann Neurol 1983; 13:217-218.

3. Womack LW, Lieselang TJ. Complications of herpes zoster ophthalmicus. Arch Ophthalmol 1983; 101: 42-45.

4. Younger DS, Hays AP, Brust JCM, Rowland LP. Granulomatous angiitis of the brain. Arch Neurol 1988; 45: 514-518. 